\title{
Deleterious Homologous Recombination Pathway Gene Mutation
}

National Cancer Institute

\section{Source}

National Cancer Institute. Deleterious Homologous Recombination Pathway Gene

Mutation. NCl Thesaurus. Code C141248.

A change in the nucleotide sequence of a gene involved in homologous recombinationtype DNA repair processes that is associated with increased risk of disease. 